\title{
A paradigm shift in pulmonary arterial hypertension management
}

\author{
Lewis J. Rubin', Nazzareno Galiè2, Gérald Simonneau ${ }^{3,4,5}$ and \\ Vallerie McLaughlin ${ }^{6}$
}

\begin{abstract}
Affiliations: 'Division of Pulmonary and Critical Care Medicine, University of California, San Diego, CA, and ${ }^{6}$ Dept of Internal Medicine, University of Michigan, Ann Arbor, MI, USA. ${ }^{2}$ Dept of Experimental, Diagnostic and Specialty Medicine - DIMES, University of Bologna, Bologna, Italy. ${ }^{3}$ Université Paris-Sud, Le Kremlin-Bicêtre, ${ }^{4}$ AP-HP, Service de Pneumologie, TORINO Thorax Innovation, Hôpital Bicêtre, Le Kremlin-Bicêtre, and ${ }^{5}$ INSERM U999, LabEx LERMIT, Centre Chirurgical Marie Lannelongue, Le Plessis Robinson, France.
\end{abstract}

Correspondence: L.J. Rubin, Division of Pulmonary and Critical Care Medicine, University of California, San Diego, 9300 Campus Point Drive \#7381, La Jolla, CA 92037-7381, USA. E-mail: ljralewisrubinmd.com

$\mathbf{0}$

@ERSpublications

A paradigm shift in pulmonary arterial hypertension management http://ow.ly/oYQnY

At the end of 2013 clinicians managing pulmonary arterial hypertension (PAH) patients have many more treatment options available to them than they did two decades ago. Basic and clinical research continue to expand treatment options but, in a changing PAH environment, there is a need to move away from trials with primary end-points that merely demonstrate short-term improvements in function to large scale trials utilising robust end-points that reflect long-term morbidity and mortality [1].

The reviews in this issue of the European Respiratory Review discuss this evolution of study design and management of patients with PAH. The authors, all experts in the field of pulmonary hypertension, delivered the presentations upon which the articles are based at the 12th International Pulmonary Hypertension Forum in April 2013 in Hamburg, Germany. This annual platform for the exchange of knowledge and experience among clinicians and researchers was attended by over 1000 healthcare professionals from all over the world, highlighting the continuing interest in PAH.

All oral therapies currently available for the management of PAH have been approved based on change in 6-min walk distance (6MWD) over a short 12-16-week study period [2-6]. The 6MWD is a simple, inexpensive, reproducible test that has allowed the rapid expansion of therapeutic options in PAH, and remains a valuable, clinically important measure of symptomatic improvement. However, in today's more advanced PAH field, its utility as a primary end-point has been challenged. In their review, GAINE and SIMONNEAU [7] will discuss the limitations of the $6 \mathrm{MWD}$, including its reduced sensitivity in patients with milder disease [8] and the reduced ability to detect a treatment effect in patients already receiving PAH therapy [9]. With a diminishing pool of treatment naïve PAH patients this is particularly important as new agents will be evaluated in patients remaining symptomatic on initial therapy [10]. In addition, a metaanalysis of 22 randomised controlled trials found that change in $6 \mathrm{MWD}$, the primary end-point employed in registration trials of PAH therapies, was not correlated with longer term outcomes [11].

To date, national PAH registries or single-centre cohort studies have been the only source of long-term outcome data. Although the information provided by such studies is valuable, prospective randomised controlled trials are required. The limitations of 6MWD have led to the use of composite primary endpoints, consisting of morbidity and mortality events, being recommended [1]. Recommendations have been

Received: Sept 172013 | Accepted: Sept 172013

Conflict of interest: Disclosures can be found alongside the online version of this article at err.ersjournals.com

Provenance: Publication of this peer-reviewed article was supported by Actelion Pharmaceuticals Ltd, Switzerland (principal sponsor, European Respiratory Review issue 130).

Copyright CERS 2013. ERR articles are open access and distributed under the terms of the Creative Commons Attribution Non-Commercial Licence 3.0. 
made on clinically relevant components that would comprise a composite primary end-point and mandating independent adjudication of all components [1]. As discussed in the review by PRESTON et al. [12], in the event-driven SERAPHIN study [13] these recommendations were refined further to produce a robust end-point and ensure that this study demonstrated a real benefit in clinically important long-term outcomes, namely a significant reduction in the risk of morbidity or mortality. Even with a composite endpoint such trials need to recruit large numbers of patients, which is a challenge in a rare disease such as PAH. However, the SERAPHIN trial highlights that such trials can be conducted and other phase III, eventdriven, long-term morbidity and mortality trials in PAH are ongoing, e.g. GRIPHON (oral selexipag; NCT01106014 [14]), COMPASS-2 (bosentan and sildenafil versus sildenafil monotherapy; NCT00303459 [15]) and AMBITION (first-line tadalafil and ambrisentan; NCT01178073 [16]). These trials will all be completed within the next 2 years and have the potential to inform on the design of all future clinical trials in PAH.

All drugs approved for the management of PAH target established pathogenic pathways; the endothelin, nitric oxide (NO) and prostacyclin pathways $[17,18]$. Targeting these three pathways facilitates combination therapy, which is established in the treatment of PAH and has improved the outlook for PAH patients. However, despite the availability of several therapeutic options the long-term prognosis for patients with PAH remains unsatisfactory [19-21]. Ongoing research efforts focused on identifying targets within novel pathogenic pathways and improved drugs acting on known pathways are discussed in the review by GALIÈ and GHOFRANI [22]. New drugs that are in advanced development and target existing pathways are macitentan (endothelin pathway), selexipag (prostacyclin pathway) and riociguat (NO pathway). Imatinib is the first non-vasoactive drug to enter phase III clinical development. Preclinical and small clinical studies are evaluating future candidate therapies that target new pathways.

$\mathrm{PAH}$ is a rapidly progressing disease, even in patients with mild symptoms [23], underlining the need for prompt diagnosis. Early diagnosis is confounded by the subtle, nonspecific nature of symptoms and by a low index of suspicion. However, as discussed in the review by SCHWAIGER et al. [24], screening of at-risk patient populations can identify PAH earlier, facilitating earlier treatment and improving prognosis [25]. The recently published DETECT study systematically evaluated 112 noninvasive screening tests in 466 systemic sclerosis patients who had undergone right heart catheterisation (RHC). The resulting algorithm is highly sensitive and misses fewer diagnoses than the European Society of Cardiology/European Respiratory Society guidelines [26]. The challenge with screening in PAH is to strike the right balance between the rate of missed diagnoses and the rate of RHC. The DETECT algorithm will help rheumatologists decide in which patients referral for RHC is warranted, which in turn should optimise resource utilisation.

$\mathrm{PAH}$ is a disease characterised by a progressive increase in pulmonary vascular resistance. However, it has subsequent effects on the right ventricle that ultimately lead to death [27]. Measures of right ventricular function are important in determining prognosis and in some cases evaluating response to treatment [28-32]. As a consequence it is critical to monitor right ventricular function. In the review by PEACOCK and VONK NOORDEGRAAF [33], the authors compare cardiac magnetic resonance imaging (CMRI) with other modalities for monitoring PAH patients. They highlight inherent difficulties in assessing the complex structure of the right ventricle based on two-dimensional images obtained with conventional echocardiography, which is compounded by inter-operator variability. They suggest that given the key role of the right ventricle in the progression of $\mathrm{PAH}$, three-dimensional CMRI alone or in combination with other noninvasive tools is likely to become increasingly important in the routine assessment and monitoring of PAH patients and, with validation, may become a routine measure in clinical trials.

GUILLEvin et al. [34] report the results of a survey that examined the substantial financial, emotional and social impact of PAH on patients and their caregivers. Their study highlights the need for PAH patients not only to receive appropriate medical and surgical care but also psychological and emotional support from their communities.

Finally, Dimopoulos [35] highlights an often neglected patient population; patients with PAH due to congenital heart disease (CHD). Patients with PAH-CHD are initially under the care of a small number of specialised paediatric cardiologists. However, due to advances in therapy these patients are living longer and transitioning to the care of specialists who deal with adult patients. As such, they present a unique challenge not shared with other forms of PAH. DimOpoulos [35] presents the case of a patient diagnosed with Eisenmenger syndrome due to a large patent ductus arteriosus and discusses optimal diagnosis and treatment options based on available evidence and expert consensus.

The reviews in this issue of the European Respiratory Review highlight the continued evolution of the PAH field. Within the next few years drugs will be available that have a demonstrated effect on the clinically relevant outcomes of morbidity and mortality, with new pathways emerging as potential targets for continuing pre-clinical research. Such progress must continue if $\mathrm{PAH}$ is to eventually become a curable disease. 


\section{Acknowledgments}

Medical writing support was provided by Julia Heagerty (Elements Communications Ltd, Westerham, UK) and supported by Actelion Pharmaceuticals Ltd (Allschwil, Switzerland).

\section{References}

1 McLaughlin VV, Badesch DB, Delcroix M, et al. Endpoints and clinical trial design in pulmonary arterial hypertension. J Am Coll Cardiol 2009; 54: Suppl. 1, S97-S107

2 Channick RN, Simonneau G, Sitbon O, et al. Effects of the dual endothelin receptor antagonist bosentan in patients with pulmonary hypertension: a randomised placebo-controlled study. Lancet 2001; 358: 1119-1123.

3 Rubin LJ, Badesch DB, Barst RJ, et al. Bosentan therapy for pulmonary arterial hypertension. N Engl J Med 2002; 346: 896-903.

4 Galiè N, Ghofrani HA, Torbicki A, et al. Sildenafil citrate therapy for pulmonary arterial hypertension. $N$ Engl J Med 2005; 353: 2148-2157.

5 Galiè N, Olschewski H, Oudiz RJ, et al. Ambrisentan for the treatment of pulmonary arterial hypertension: results of the ambrisentan in pulmonary arterial hypertension, randomized, double-blind, placebo-controlled, multicenter, efficacy (ARIES) study 1 and 2. Circulation 2008; 117: 3010-3019.

6 Galiè N, Brundage BH, Ghofrani HA, et al. Tadalafil therapy for pulmonary arterial hypertension. Circulation 2009; 119: 2894-2903.

7 Gaine S, Simonneau G. The need to move from 6-minute walk distance to outcome trials in pulmonary arterial hypertension. Eur Respir Rev 2013; 22: 487-494.

8 Frost AE, Langleben D, Oudiz R, et al. The 6-min walk test (6MW) as an efficacy endpoint in pulmonary arterial hypertension clinical trials: demonstration of a ceiling effect. Vascul Pharmacol 2005; 43: 36-39.

9 Snow JL, Kawut SM. Surrogate end points in pulmonary arterial hypertension: assessing the response to therapy. Clin Chest Med 2007; 28: 75-89.

10 Rubin LJ. The 6-minute walk test in pulmonary arterial hypertension: how far is enough? Am J Respir Crit Care Med 2012; 186: 396-397.

11 Savarese G, Paolillo S, Costanzo P, et al. Do changes of 6-minute walk distance predict clinical events in patients with pulmonary arterial hypertension? A meta-analysis of 22 randomized trials. J Am Coll Cardiol 2012; 60: 1192-1201.

12 Preston IR, Suissa S, Humbert M. New perspectives in long-term outcomes in clinical trials of pulmonary arterial hypertension. Eur Respir Rev 2013; 22: 495-502.

13 Pulido T, Adzeriko I, Channick R, et al. Macitentan and morbidity and mortality in pulmonary arterial hypertension. N Engl J Med 2013; 369: 809-818.

14 Actelion. A multicenter, double-blind, placebo-controlled phase 3 study to demonstrate the efficacy and safety of ACT-293987 in patients with pulmonary arterial hypertension. NCT01106014. http://clinicaltrials.gov/ct2/show/ NCT01106014 Date last accessed: June 19, 2013. Date last updated: September 3, 2013.

15 Actelion. Effects of the combination of bosentan and sildenafil versus sildenafil monotherapy on pulmonary arterial hypertension (PAH) (Compass 2). NCT00303459. http://clinicaltrials.gov/show/nct00303459 Date last accessed: June 19, 2013. Date last updated: August 30, 2013.

16 GlaxoSmithKline. A randomised, multicenter study of first-line ambrisentan and tadalafil combination therapy in subjects with pulmonary arterial hypertension (PAH). NCT01178073. http://clinicaltrials.gov/show/NCT01178073 Date last accessed: June 19, 2013. Date last updated: June 6, 2013.

17 Humbert M, Sitbon O, Simonneau G. Treatment of pulmonary arterial hypertension. N Engl J Med 2004; 351; $1425-1436$.

18 Sitbon O, Morrell N. Pathways in pulmonary arterial hypertension - the future is here. Eur Respir Rev 2012; 21: 321-327.

19 Humbert M, Sitbon O, Chaouat A, et al. Survival in patients with idiopathic, familial, and anorexigen-associated pulmonary arterial hypertension in the modern management era. Circulation 2010; 122: 156-163.

20 Ling Y, Johnson MK, Kiely DG, et al. Changing demographics, epidemiology, and survival of incident pulmonary arterial hypertension: results from the pulmonary hypertension registry of the United Kingdom and Ireland. Am J Respir Crit Care Med 2012; 186: 790-796.

21 Benza RL, Miller DP, Barst RJ, et al. An evaluation of long-term survival from time of diagnosis in pulmonary arterial hypertension from the REVEAL Registry. Chest 2012; 142: 448-456.

22 Galiè N, Ghofrani A-H. New horizons in pulmonary arterial hypertension therapies. Eur Respir Rev 2013; 22: 503-514.

23 Galiè N, Rubin LJ, Hoeper M, et al. Treatment of patients with mildly symptomatic pulmonary arterial hypertension with bosentan (EARLY study): a double-blind, randomised controlled trial. Lancet 2008; 371: 2093-2100.

24 Schwaiger JP, Khanna D, Coghlan JG. Screening patients with scleroderma for pulmonary arterial hypertension and implications for other at-risk populations. Eur Respir Rev 2013; 22: 515-525.

25 Humbert M, Yaici A, de Groote P, et al. Screening for pulmonary arterial hypertension in patients with systemic sclerosis: clinical characteristics at diagnosis and long-term survival. Arthritis Rheum 2011; 63: 3522-3530.

26 Coghlan JG, Denton CP, Grünig E, et al. Evidence-based detection of pulmonary arterial hypertension in systemic sclerosis: the DETECT study. Ann Rheum Dis 2013 [In press DOI: 10.1136/annrheumdis-2013-203301].

27 Voelkel NF, Gomez-Arroyo J, Abbate A, et al. Pathobiology of pulmonary arterial hypertension and right ventricular failure. Eur Respir J 2012; 40: 1555-1565.

28 D’Alonzo GE, Barst RJ, Ayres SM, et al. Survival in patients with primary pulmonary hypertension. Results from a national prospective registry. Ann Intern Med 1991; 115: 343-349.

29 van Wolferen SA, Marcus JT, Boonstra A, et al. Prognostic value of right ventricular mass, volume, and function in idiopathic pulmonary arterial hypertension. Eur Heart J 2007; 28: 1250-1257.

30 van Wolferen SA, van de Veerdonk MC, Mauritz GJ, et al. Clinically significant change in stroke volume in pulmonary hypertension. Chest 2011; 139: 1003-1009. 
31 van de Veerdonk MC, Kind T, Marcus JT, et al. Progressive right ventricular dysfunction in patients with pulmonary arterial hypertension responding to therapy. J Am Coll Cardiol 2011; 58: 2511-2519.

32 Forfia PR, Fisher MR, Mathai SC, et al. Tricuspid annular displacement predicts survival in pulmonary hypertension. Am J Respir Crit Care Med 2006; 174: 1034-1041.

33 Peacock AJ, Vonk Noordegraaf A. Cardiac magnetic resonance imaging in pulmonary arterial hypertension. Eur Respir Rev 2013; 22: 526-534.

34 Guillevin L, Armstrong I, Aldrighetti R, et al. Understanding the impact of pulmonary arterial hypertension on patients' and carers' lives. Eur Respir Rev 2013; 22: 535-542.

35 Dimopoulos K. Eisenmenger syndrome in an adult patient with a large patent ductus arteriosus. Eur Respir Rev 2013; 22: 558-564. 